\title{
Evaluation of the Effect of Various Antioxidants on the Shear Bond Strength of the Composite Resin to the Bleached Enamel: An In Vitro study
}

\author{
Somya Jain ${ }^{1}$ Neetu Jindal ${ }^{1}$ Renu Agarwal ${ }^{1}$ Ajisha Raju ${ }^{1}$ Shallu Bansal ${ }^{2}$ \\ ${ }^{1}$ Department of Conservative Dentistry and Endodontics, Surendera \\ Dental College and Research Institute, Sri Ganganagar, Rajasthan, \\ India \\ 2 Department of Oral and Maxillofacial Surgery, Swargiya Dadasaheb \\ Address for correspondence Somya Jain, MDS, Department of \\ Conservative Dentistry and Endodontics, Surendera Dental College \\ and Research Institute, Sri Ganganagar 335001, Rajasthan, India \\ (e-mail: jainsomya.sunanda@gmail.com).
} Kalmegh Smruti Dental College and Hospital, Nagpur, Maharashtra, India

Dent J Adv Stud 2021;9:133-137.

\begin{abstract}
Keywords

- antioxidants

- bleached enamel

- shear bond strength

Objective Various intrinsic and extrinsic stains cause discolored teeth, which is of great concern to patients, which can be treated by bleaching, enamel microabrasion, veneers, and crowns. However, bleaching leads to reduced bond strength if adhesive restorations are performed immediately.

Thus, the application of antioxidant agents after bleaching has been recommended, which are proved to act as free radical scavengers, improving the bond strength.

Materials and Methods A total of 120 extracted human maxillary incisor teeth were taken. Using a slow-speed diamond saw and a water coolant spray, the roots of all the teeth were removed approximately $2 \mathrm{~mm}$ below the cementoenamel junction. With the labial surface facing upward, each sectioned sample was embedded in the acrylic resin. Then, the central portion of the embedded tooth was ground flattened with 600grit silicon carbide paper such that the labial enamel surface becomes smooth and evenly flat.

All 120 samples were divided into two control groups $(n=20)$, i.e., positive control group $(n=10)$ and negative control group $(n=10)$ and five experimental groups $(n=100)$, such that each experimental group had 20 samples.

The enamel surface in both the control groups and groups treated with antioxidants was thoroughly rinsed off with distilled water for 30 seconds and subjected to bonding procedure.

Result Significant differences were observed among the experimental groups $(p<0.05)$. The samples that were treated with $10 \%$ sodium ascorbate (group III) demonstrated significantly higher mean shear bond strength than the other experimental groups $(p<0.05)$.
\end{abstract}

published online October 25, 2021
DOI https://doi.org/

$10.1055 / \mathrm{s}-0041-1736264$. ISSN 2321-1482. (c) 2021. Bhojia Dental College and Hospital affiliated to Himachal Pradesh University. All rights reserved.

This is an open access article published by Thieme under the terms of the Creative Commons Attribution-NonDerivative-NonCommercial-License, permitting copying and reproduction so long as the original work is given appropriate credit. Contents may not be used for commercial purposes, or adapted, remixed, transformed or built upon. (https://creativecommons.org/ licenses/by-nc-nd/4.0/)

Thieme Medical and Scientific Publishers Pvt. Ltd., A-12, 2nd Floor, Sector 2, Noida-201301 UP, India 


\section{Introduction}

Esthetic excellence is achieved by conjunction of various restorative treatments and vital bleaching procedures. When used alone, vital bleaching has proved to be a safe and conservative method but when used in conjugation with various restorative materials, its mechanism of action has shown deduction in the physical properties of various restorative materials.

Accreditation of the sparse, short, and poorly defined resin tags goes to the modified inorganic and organic composition of the bleached enamel surface after immediate treatment with peroxide-based bleaching agents. Thus, bond strength of resin to enamel accounts for the quality of these tags, their incidence, and their depth of penetration. ${ }^{1}$

Thus, the important complication following bleaching procedure is decreased bond strength of composite resin to bleached enamel. ${ }^{2}$

Various clinicians suggested a delay of 2 to 3 days following bleaching to perform all restorative procedures, which has further trammeled the immediate esthetic procedure. However, the use of various herbal and synthetic antioxidants to curb the effect of free radicals following bleaching procedure, enabling the restorative procedures to be performed immediately, has been proposed by several recent studies, as antioxidants have shown to have free radical scavenging ability, which can reverse the reduced bond strength of resin to bleached enamel. ${ }^{3}$

Thus, the aim of this study is an in vitro evaluation of the effect of various antioxidants on the shear bond strength of the composite resin to the bleached enamel.

\section{Materials and Method}

A total of 120 human, single-rooted, caries-free, maxillary incisors, extracted for periodontal reasons, were taken for the study. The inclusion criteria were as follows: teeth that were intact, noncarious, and freshly extracted due to periodontal disease or orthodontic purposes.

All the teeth were examined with the stereomicroscope under $\times 20$ magnification to exclude the teeth with cracks, fracture lines, caries, developmental anomalies, and existing restorations. Also, the teeth with extrinsic and intrinsic discolorations were also excluded from the study.

Samples were stored in distilled water until mounting to prevent bacterial growth. The roots of all teeth were sectioned transversally $2 \mathrm{~mm}$ below the cementoenamel junction using a slow-speed diamond saw under a water coolant spray. Then, each sectioned coronal sample was embedded in the acrylic resin with the labial surface facing upward. Then, the central portion of the embedded tooth was ground flattened with 600-grit silicon carbide paper such that the labial enamel surface becomes smooth and evenly flat for bonding to composite resin.

\section{Preparation of Antioxidants (-Fig. 1)}

All the antioxidants were water-soluble except alpha tocopherol, which was soluble in ethyl alcohol, and lycopene, which was prepared in chloroform.

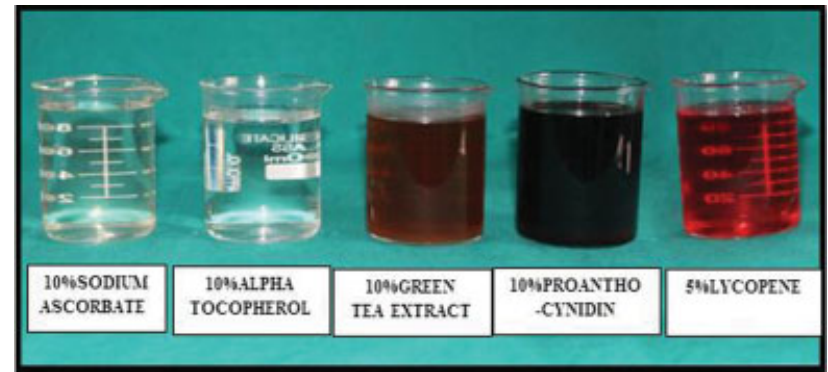

Fig. 1 Antioxidants used in the study.

\section{Division of Groups}

All 120 samples were divided into two control groups $(n=20)$, that is, positive control group $(n=10)$ and negative control group $(n=10)$, and five experimental groups ( $n=100)$ such that each experimental group had 20 samples. All the samples except positive control group were bleached with $37.5 \%$ hydrogen peroxide bleaching gel (Pola Office, SDI South East Australia) in 3 sessions for each consecutive 8 minutes. The gel was completely rinsed off with distilled water. Except the control groups, experimental groups were further subdivided into subgroups on the basis of antioxidant treatment. This was then followed by building of composite cylinder on the labial surface of each sample in all the groups.

Thus, the positive control group remained unbleached and the negative control group was bleached but received no antioxidant treatment.

\section{Antioxidant Treatment}

In the experimental groups, after bleaching with $37.5 \%$ hydrogen peroxide, antioxidant treatment was done with $10 \mathrm{~mL}$ of antioxidant solution applied on enamel surfaces of all 100 samples, as an irrigating solution, for 10 minutes with a flow rate of $1 \mathrm{~mL} / \mathrm{min}$ with the $10 \mathrm{~mL}$ syringe (-Table 1 ).

\section{Bonding Procedure (-Fig. 2)}

A piece of plastic hollow cylinder $2 \mathrm{~mm}$ in diameter and $4 \mathrm{~mm}$ in height was positioned in the center of the flattened portion of enamel of all the samples. Then, 37\% phosphoric acid gel (Ivoclar Eco-Etch) was applied on the demarcated area for 15 seconds for the purpose of etching. Then, the etchant was rinsed with water syringe for 5 seconds and dried with three-way syringe. This was followed by application of bonding agent (Ivoclar Tetric $\mathrm{N}$ bond) with the

Table 1 Division of samples on the basis of antioxidants used

\begin{tabular}{|l|l|}
\hline Experimental groups & Antioxidants \\
\hline Group $3(n=20)$ & Bleached $+10 \%$ sodium ascorbate \\
\hline Group $4(n=20)$ & Bleached $+10 \%$ alpha tocopherol \\
\hline Group $5(n=20)$ & Bleached $+5 \%$ proanthocyanidin \\
\hline Group $6(n=20)$ & Bleached $+10 \%$ green tea extract \\
\hline Group $7(n=20)$ & Bleached $+10 \%$ lycopene \\
\hline
\end{tabular}

Note: The enamel surface of both the control groups and experimental groups was thoroughly rinsed off with distilled water for 30 seconds and subjected to bonding procedure. 


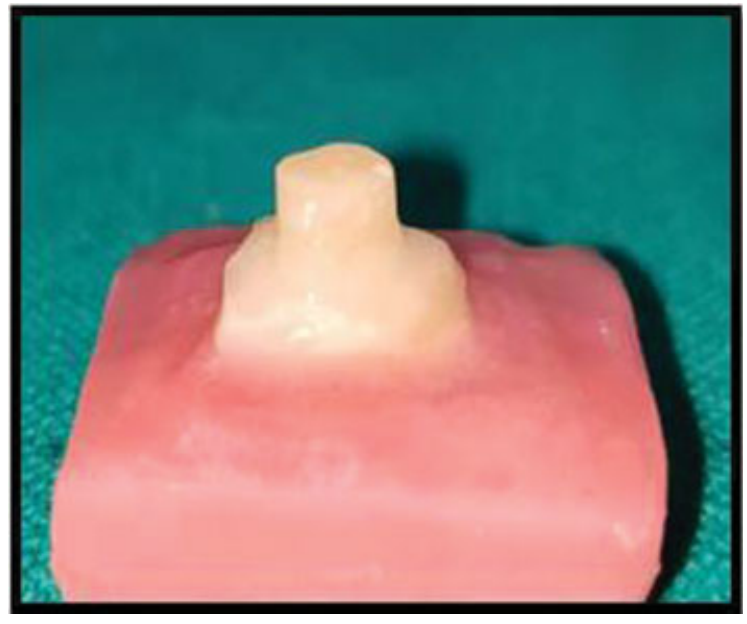

Fig. 2 Composite cylinder bonded to the labial surface of the tooth.

applicator tip, gentle drying, and curing for 10 seconds using a Light Curing Unit (Woodpecker led curing light). Then, two increments of 2-mm diameter of composite resin (Ivoclar Te-Econom plus) were placed, each was light cured for 40 seconds separately. Composite resin cylinder of $2 \mathrm{~mm}$ in diameter and $4 \mathrm{~mm}$ in depth was built. The piece of plastic cylinder was cut and removed. The samples were stored in distilled water till testing for shear bond strength.

\section{Testing Procedure (-Fig. 3)}

The samples were tested for the shear bond strength under Universal Testing Machine (Shimadzu, Japan). A knife edge shearing rod with a crosshead speed of $0.5 \mathrm{~mm} / \mathrm{min}$ was used. The force was applied perpendicular at the interface of

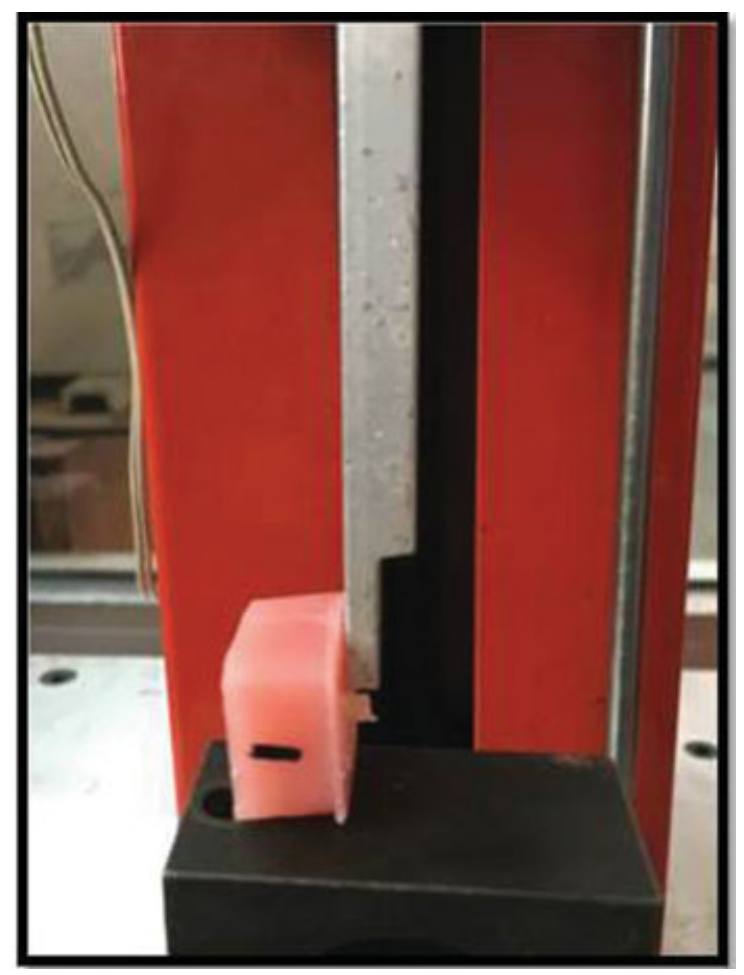

Fig. 3 Testing procedure. enamel surface and the bonded composite cylinder. The load at failure is recorded by laboratory tech notebook software version 6.3. The shear bond strengths of the specimens was calculated and expressed in MPa.

After that statistical analysis was performed using oneway ANOVA and posthoc Tukey's HSD test.

\section{Results}

The present in vitro study was designed for evaluation of the effect of various antioxidants on the shear bond strength of the composite resin to the bleached enamel.

Significant differences were observed among the study groups $(p<0.05)$. Groups I and II demonstrated the highest and lowest mean shear bond strength values, respectively. The samples that were treated with $10 \%$ sodium ascorbate (group III) demonstrated significantly higher mean shear bond strength than other experimental groups as shown in - Table $1(p<0.05)$. No significant differences were found between 10\% alpha tocopherol (group IV) and 10\% proanthocyanidin (group VI) and also comparison between green tea extract (group V) and 5\% lycopene (group VII) showed nonsignificant difference $(p>0.05)$, as shown in - Table 2 (see also - Fig. 4).

\section{Discussion}

The long-term durability of various restorative materials is compromised due to the deleterious side effects of bleaching procedures, possibly credited to the residues from hydrogen peroxide degradation that are known to have low molecular weight. This facilitates their penetration into the enamel tooth surface, affecting the polymerization of adhesive systems and resin composite. ${ }^{2}$

Thus, to reverse the reduced bond strength, antioxidants were used prior to the composite bonding, as there action takes place by scavenging the residual peroxide radicals, which was also stated by Lai et al, in that use of antioxidants could reverse the deterioration caused by inclusion of peroxide ions. ${ }^{4}$

In the present study, intragroup comparison of various antioxidants showed that $10 \%$ sodium ascorbate (group III) caused maximum reversal of shear bond strength $(139.45 \pm 10.16)$ when compared with other experimental groups.

Sodium ascorbate, being a reducing agent, scavenges the free radical through the mechanism of passive detoxification, which is accomplished by donating two high-energy electrons. The results of this study were in accordance with previous investigations done by Lai et al. ${ }^{4}$ Also, being watersoluble with low-molecular weight of $198.11 \mathrm{~g} / \mathrm{mol}$ enables sodium ascorbate to penetrate better. ${ }^{5}$

Even $10 \%$ alpha tocopherol (group IV) showed significantly higher bond strength values as compared with both $10 \%$ green tea extract (group V) and 5\% lycopene (group VII). This inference was supported by Ratih et al. ${ }^{6}$

Water insolubility and presence of alcohol in the composition of $10 \%$ alpha tocopherol could be credited enough for 
Table 2 Demonstrates the intragroup mean and SD values of shear bond strength $(N)$ for different groups by using one-way ANOVA

\begin{tabular}{|c|c|c|c|c|c|}
\hline Groups & $\begin{array}{l}\text { Mean } \\
(N)\end{array}$ & SD & $F$ & $p$-Value & Status \\
\hline $\begin{array}{l}\text { Positive control } \\
\text { (group I) }\end{array}$ & 174.5 & 24.54 & \multirow[t]{8}{*}{109.677} & \multirow[t]{8}{*}{$0.00^{\mathrm{a}}$} & \multirow[t]{8}{*}{ SIG } \\
\hline $\begin{array}{l}\text { Negative control } \\
\text { (group II) }\end{array}$ & 42 & 10.32 & & & \\
\hline $\begin{array}{l}10 \% \text { sodium ascorbate } \\
\text { (group III) }\end{array}$ & 139.45 & 10.16 & & & \\
\hline $\begin{array}{l}10 \% \text { alpha tocopherol } \\
\text { (group IV) }\end{array}$ & 108.1 & 13.08 & & & \\
\hline $\begin{array}{l}10 \% \text { green tea extract } \\
\text { (group V) }\end{array}$ & 78 & 15.04 & & & \\
\hline $\begin{array}{l}10 \% \text { proanthocynidin } \\
\text { (group VI) }\end{array}$ & 97.9 & 17.58 & & & \\
\hline $\begin{array}{l}\text { 5\% lycopene } \\
\text { (group VII) }\end{array}$ & 70.2 & 14.22 & & & \\
\hline Total & 100.31 & 38.31 & & & \\
\hline
\end{tabular}

Abbreviation: SD, standard deviation.

${ }^{\mathrm{a}}$ The mean difference is significant at the 0.05 level.

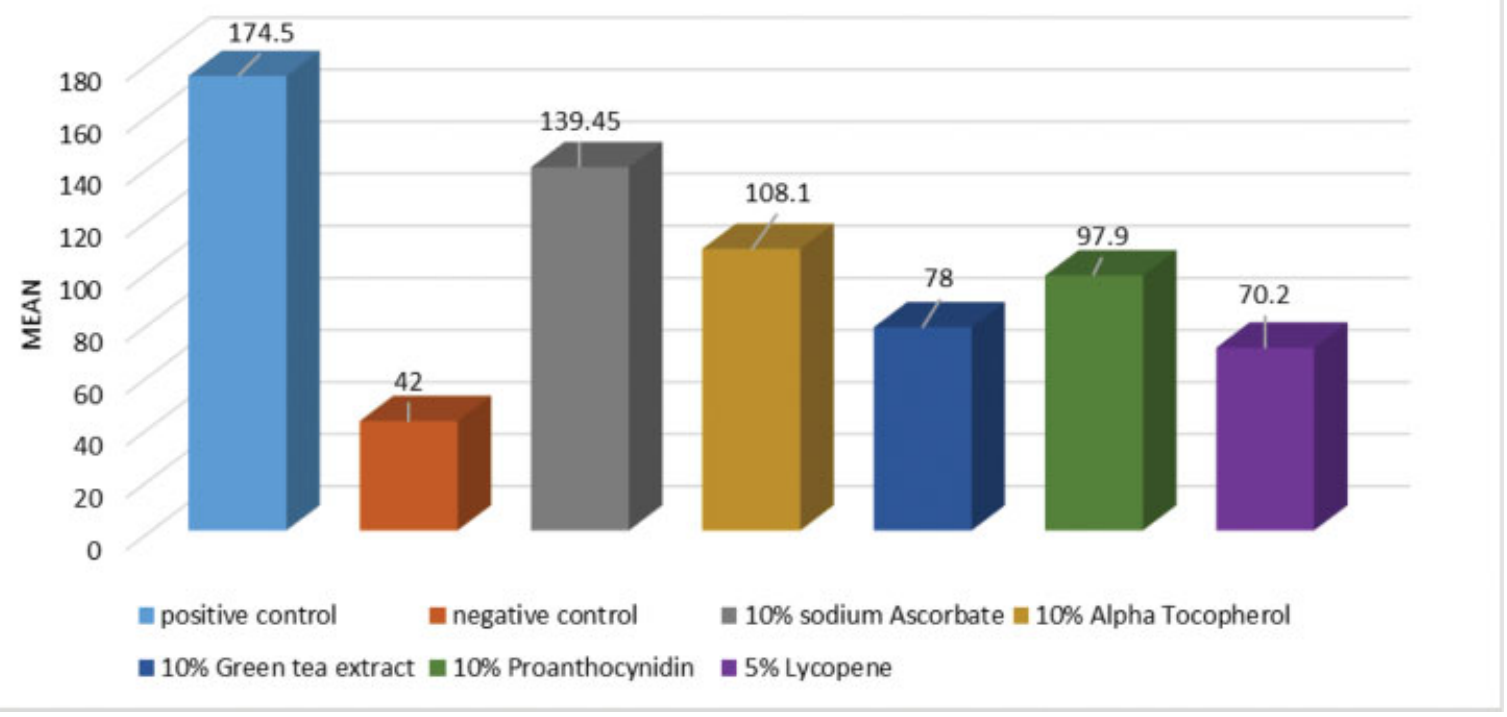

Fig. 4 Demonstrate the mean shear bond strength comparison of all the groups.

depicting the increased shear bond strength values. This inference was supported by Sasaki et al. ${ }^{7}$

However, the difference between group IV (10\% alpha tocopherol) and group VI (10\% proanthocyanidin) were nonsignificant with value $p>0.05$. This inference was not supported by a previous study done by Manoharan et al and Vidhya et al, who concluded that $10 \%$ proanthocyanidin showed significantly higher results as compared with $10 \%$ alpha tocopherol. ${ }^{8}$

Results of the present study revealed that the reversal of mean shear bond strength done by $10 \%$ proanthocyanidin (group VI) was much less than that of $10 \%$ sodium ascorbate (group III), which could be due to the higher molecular weight of tannins (500-3,000 g/mol), ${ }^{9}$ the category to which proanthocyanidin belongs. This inference was favored by Arumugam et al. ${ }^{2}$

Intragroup comparison of the present study revealed that group VI (10\% proanthocyanidin) showed significantly higher shear bond strength value $(p<0.05)$ as compared with the group V (10\% green tea) and group VII (5\% lycopene).

Late et al in his study inferred that $10 \%$ proanthocyanidin is a natural collagen cross-linker that can increase collagen synthesis and decrease the degradation of collagen, all of which strengthen the properties of resin bond. Thus, this inference could be credited to the more effective antioxidant property of proanthocyanidin than $10 \%$ lycopene. ${ }^{10}$

It was speculated that higher concentrations of green tea applied for longer period of time may result in a greater 
reversal of bond strength values in bleached enamel. ${ }^{6}$ This could be attributed to the presence of catechins in the green tea, such as EGCG and EGC, which are potent antioxidants. ${ }^{8}$ This inference was supported by a study done by Ozelin et al. ${ }^{11}$

The bond strength values obtained for $5 \%$ lycopene (group VII) were not statistically significant as compared with group V (10\% green tea extract), which had mean shear bond strength value of $78 \pm 15.04$.

The limited diffusion potential across the enamel surface enables lycopene to trap free radicals, which could be due to its least water solubility. This also explains its lowest bond strength value, that is, $70.2 \pm 14.22$, among the antioxidant group, as concluded by Dhingra et al. ${ }^{12}$

However, a study done by Khamverdi et al was not in favor of our study, who concluded that herbal antioxidants were 20 times better than the sodium ascorbate when they evaluated the effect of herbal antioxidants on the shear bond strength of composite resin to the bleached enamel. $^{3}$

So, the need of the hour is to conduct further studies to evaluate the antioxidant potential of various herbal and synthetic antioxidants for the purpose of determining the stability of their activity by reducing their application time and increasing their concentration in various solution and gel formulations. Moreover, failure mode and scanning electron microscope evaluations of enamel composite interface should be performed in future studies.

\section{Conclusions}

Within the limitations of the study, it could be concluded that bleaching with $37.5 \%$ HP adversely affected the enamel composite bond strength when the bonding procedure was performed immediately after bleaching, although none of the antioxidants were able to completely reverse the mean shear bond strength to the base line value. However, $10 \%$ sodium ascorbate caused maximal reversal of the shear bond strength.
Conflict of Interest

None declared.

\section{References}

1 Kavitha M, Selvaraj S, Khetarpal A, Raj A, Pasupathy S, Shekar S. Comparative evaluation of superoxide dismutase, alpha-tocopherol, and $10 \%$ sodium ascorbate on reversal of shear bond strength of bleached enamel: An in vitro study. Eur J Dent 2016;10(01):109-115

2 Arumugam MT, Nesamani R, Kittappa K, Sanjeev K, Sekar M. Effect of various antioxidants on the shear bond strength of composite resin to bleached enamel: an in vitro study. J Conserv Dent 2014; 17(01):22-26

3 Khamverdi Z, Khadem P, Soltanian A, Azizi M. In-vitro evaluation of the effect of herbal antioxidants on shear bond strength of composite resin to bleached enamel. J Dent (Tehran) 2016;13(04): 244-251

4 Lai SCN, Tay FR, Cheung GSP, et al. Reversal of compromised bonding in bleached enamel. J Dent Res 2002;81(07):477-481

5 Aguilar F, Autrup H, Barlow S, et al. Use of lycopene as a food colour scientific opinion of the panel on food additives, flavourings, processing aids and materials in contact withfood. Eur Food Saf Authority J 2008;674:1-66

6 Nari-Ratih D, Widyastuti A. Effect of antioxidants on the shear bond strength of composite resin to enamel following extracoronal bleaching. J Clin Exp Dent 2019;11(02):e126-e132

7 Sasaki RT, Flório FM, Basting RT. Effect of $10 \%$ sodium ascorbate and $10 \% \alpha$-tocopherol in different formulations on the shear bond strength of enamel and dentin submitted to a home-use bleaching treatment. Oper Dent 2009;34(06):746-752

8 Shashibhushan KK, Manoharan M, Poornima P, Reddy VVS. Effect of novel herbal products on the bond strength of composite on bleached enamel. Int J Dent Med Res 2015;1(05):20-23

9 Porter WM, Hemingway LJ. Molecular weight profile of proanthocyanidin polymer. Phytochemistry 1983;22:569-572

10 Late L, Daokar S, Kulkarni P, Tambake R, Mapari P, Pophli S. Evaluation of grape seed extract (Vitis Vinifera) as a crosslinker on the stability of dentine collagen in total-etch adhesive systems: an in vitro study. Asian J Pharm Clin Res 2019;12(05):164-166

11 Ozelin AA, Guiraldo RD, Carvalho RVD, Lopes MB, Berger SB. Effects of green tea application time on bond strength after enamel bleaching. Braz Dent J 2014;25(05):399-403

12 Dhingra A, Gupta AK, Minocha A, Sen N. Comparative evaluation of immediate bond strength to bleached enamel following application of various antioxidant solutions. DJAS 2017;5(02):84-89 